SHS Web of Conferences 6, 03012 (2014)

DOI: $10.1051 /$ shsconf / 20140603012

(C) Owned by the authors, published by EDP Sciences, 2014

\title{
Analyses the Status Quo and Countermeasures of Prevention and Control of the Rural Disease
}

\author{
Zhu Bifa, Xie Hui \\ Hubei university of Chinese medicine, 430065 Wuhan Hubei, China
}

\begin{abstract}
The report of the eighteenth national congress of the communist party of China has indicated that we should improve the rural three-level health service network and perfect urban community health service system. But, in the 21 st century, the prevalence of the rural population is still growing and the rural disease prevention and control work is still tough, how to break the phenomenon caused by illness among the rural people., become a problem to be solved facing the whole society, and develop the rural medical and health undertakings, and to improve the backward situation in the rural medical and health care is an important content of construction of new socialist countryside; Based on the analysis of the current situation of rural disease prevention and control, puts forward a series of countermeasures and Suggestions of the importance to rural health education, increase government investment in health, to perfect the new rural cooperative medical care system .
\end{abstract}

Keywords. rural disease; the status quo; countermeasures

\section{Introduction}

China is a socialist country, and at the same time is an agricultural country, farmer is the main productive forces in the country. Large proportion of the rural population in China, covering an area of extensive,due to the emergence of the phenomenon of urbanization, the rural population mobility also increases accordingly, and the countryside by the low degree of education, rural medical business personnel quality is low, medical equipment and technology backwardness lead to rural population risk increases greatly. In today's reform and opening up, due to the widening gap between rich and poor, the rise in the price of medical services and drugs, the imperfect rural traffic measures development factors contributed to the phenomenon of farmers' medical care. Therefore, the discussion on the situation of rural diseases, analysis of its causes, identify effective preventive measures is a matter of urgency.

\section{Current situation of rural development of disease control and prevention}

Under the push of government, rural work of disease prevention and control in China has made remarkable achievements. Since the implementation of the cold chain in the country operation, the planned immunization programmes, as well as non-routine immunization, measles, diphtheria, whooping cough, epidemic encephalitis $b$, the incidence of hepatitis $b$ and other relevant infectious 
diseases greatly reduced, formed the extinction of smallpox, polio, effectively control the good situation of endemic diseases and parasitic diseases. However, as the change of environment, pathogen mutates, poses a new threat to human health, at the same time, the incidence of chronic noncommunicable diseases is higher and higher, there is a big threat to people's health. Along with the reform of rural economic system and fiscal and taxation systems, was widely acclaimed in rural China and a three-level network of medical prevention met a great challenge, the population of damage, and inefficient management mechanism and management system is not congruent, rural work of disease prevention and control is struggling."

\section{The existing main problems and deficiencies}

\subsection{Rural health education level lags behind}

The development of rural health education occupies a prime position in the development of public health. Development of Rural health education to increase awareness and ability of self-care among rural residents. However, rural health education to a great extent, and there is no real has drawn great attention of society and the government at all levels resulting in poor rural health education institutions, rural health education strength is weak, the health education work personnel business quality is not high, the problem such as backward means of health education.

\subsection{Inadequate government health investment}

Medical and health undertakings is the livelihood of the people, inadequate government on the cause of disease prevention, failed to timely and effective capital dispatch scheme, led to the medical and health resources allocation is low, no advanced technology of the timely and effective diagnosis disease, leading to the rural population prevalence of chronic diseases, increasing year by year. As compensation form of institution of disease prevention and control from a single government funding, become a "national finances and paid service charge" led to the development of institution of disease prevention and control to the non-profit organization, and even appeared the phenomenon "heavy light service free of charge, paid services gains more light service revenue less service".

\subsection{The rural social welfare security system is not perfect}

"Three Rural" issue has always been the hot topic in the social from all walks of life. Because our country long-term heavy city light township, dig the agriculture ministry of dual economic structure, led to the rural social welfare in a weak position, the phenomenon "because the disease causes poor or return to poverty" is common occurrence. Only provide lower levels of the traditional cooperative medical welfare, cooperation each other aid is limited to the scope of the collective, is not conducive to rural social members disease medical risk dispersion in a larger scope, unable to resist the particularity of rural social members of disease and the risk of a serious illness.

\section{Disease control and prevention countermeasures in rural areas}

\subsection{Attention to health education in rural areas}

Attaches great importance to the rural health education, expand coverage for rural health education, the government should first establish reasonable training plan, make scientific business education for rural health professionals training, organizational learning "food hygiene law, the law on the prevention" and control of infectious diseases, the "regulations on the administration of public health" and other laws and regulations, improve the professional knowledge and institutionalization of assessment standards; Mobilize all the forces can be mobilized to each region targeted to carry out a series of activities, such as the column, radio, street consulting propaganda activities, who love month, 
issued by the propaganda of readable data, combined with various health day using mass media to carry on the positive and effective health education. And organize the villagers actively study advanced network knowledge, master the advanced medical theory, let the villagers come on illiteracy, the various diseases have a certain understanding, help in off-hours problems arise can early diagnosis and treatment, do not delay the best period of treatment.

\subsection{Increasing the government's health investment}

The government should increase the investment to the public health, to mobilize all forces that can be mobilized and can use the money, we will conscientiously implement health investment policies, actively promote the reform priorities; policy tilt, and all kinds of preferential policies to encourage rural doctors, the introduction of experienced high quality talents, the introduction of advanced medical technology, to improve the quality of the professional personnel, improve the level of medical treatment, at the same time, the government should vigorously develop public health service industry, improve the medical and health conditions, configure the necessary medical equipment, make work can better close to the needs of the rural health care and physical health, let common people benefit truly, truly feel the party and the government's care.

\subsection{Perfect the new rural cooperative medical system}

New type of rural cooperative medical care is to point to by the government, organization, guidance, support, farmers voluntary participation, individual, collective and government multilateral financing, mainly to the poverty-stricken farmers medical help each other in all aid system. Government should explore to adapt to the development of the region patterns, ensure the effective use of funds, to improve the farmer's medical condition was carried out on the standard medications, regular check to superior departments of the standardization system is not regular spot checks to urge the new farmers and the improvement of the management mechanism, strengthen rural vaccination work at the same time, reduce the incidence of the disease to expand benefited range, improving the benefit and convenience, make the villagers medical reimbursement ratio increased year by year, make the sickness in ankang.

\section{Conclusion}

In today's reform and opening up development, in the hope that the governments at all levels to carry out the eighteenth national congress of the communist party of China's policies, does the practical work for the villagers, all from the perspective of villagers, truly serve the people, let the villagers really feel warm, at the same time, improve the rural disease control and prevention ability, let the villagers to disease said "No" is No longer a dream, towards the footsteps of a harmonious society, truly advancing with The Times, blaze new trails.

\section{References}

1. ZhaiShenYong, liu wei, Du Jun etc. Rural system reform and the thinking of disease prevention and control [J]. Journal of preventive medicine BBS, but 28-629 (2006).

2. Hu Xiaohui. County (district) to explore the present situation and the existing problems of institution of disease prevention and control [J]. Journal of occupational health and emergency rescue. 4:18 and 6-187 (2005).

3. ChengLin. China's rural social welfare development goal mode selection [J]. Administrative college journal. 2006 (2) : 19.

4. Han Yanping. Analyses how to improve the new rural cooperative medical system [J]. China collective economy. 10 (2012). 